\title{
Rhetorical meaning
}

Susan F. Schmerling*

815 W. Slaughter Lane, Apt. 150

Austin, Texas, 78748 USA

Received June 13, 2018; Accepted August 29, 2018

\begin{abstract}
This paperintroduces rhetorical meaning to semantic theory; we use the term by analogy totropes like metonymy in classical rhetoric, which yields 'the American president' from the White House - that is, it substitutes one referential meaning for another. Here we focus on two rhetorical meanings: intensification and attenuation. Intensification is expressed in English and many other languages by total reduplication (an old old man); attenuation is exemplified by Spanish 'synthetic' diminutive forms (hombrecito 'little man'; cf. hombre 'man') and English and French 'analytic' formations (My Little Chickadee (film); petit caporal 'Little Corporal' (Napoléon Bonaparte)). Formally, a rhetorical meaning is a relation with one referential meaning as its domain and, as its codomain, a set of related referential meanings, the particular set specified by the rhetorical meaning at hand. The selection from among elements of the codomain, which can even seem contradictory out of context, is in fact highly context-dependent and indicates a critical role for pragmatics in an overall account of this meaning type.
\end{abstract}

Keywords: rhetorical meaning $\bullet$ English $\bullet$ French $\bullet$ Spanish $\bullet$ reduplication $\bullet$ diminutives $\bullet$ intensity $\bullet$ attenuation

(c) Sciendo

\section{Introduction}

This paper introduces rhetorical meaning to semantic theory. The examples I look at involve either intensification or attenuation of referential meanings; more generally, they involve the substitution of one referential meaning for a related one. This substitution is expressible formally as a relation between one referential meaning and a set of related meanings, the selection of the element of that set being highly context dependent.

The term rhetorical meaning as I use it in this paper thus pertains to a relation from one referential meaning to a non-empty set of alternatives (the particular relation depending on the specific rhetorical meaning at hand), much as the tropes of classical rhetoric substitute one referential meaning for a related one; for example, if I refer to the US executive as the White House (The White House announced today that ...), I am using the trope of metonymy. I start this paper by discussing the English rhetorical meaning of intensification, expressed, I argue, by little recognized total reduplication in that language.

The discussion in Section 2, where intensification is the rhetorical meaning in focus, centres on the example an old old man, which has occasionally been viewed as involving a problem in syntactic theory, calling into question the formal properties of rules thought to be involved in its formation. Having argued that old old is better analysed as the morphological phenomenon of total reduplication, I then use Section 3 to test the notion of rhetorical meaning I have used intensification to identify by looking at its role in the meaning of diminutive formations. Diminutives are expressions with a very different kind of grammatical structure from reduplication and a very different kind of meaning substitution. Nevertheless, the rhetorical meaning expressed by a diminutive formation, which I will argue is the attenuation of referential meaning, has the same overall formal structure as intensification. ${ }^{1}$

1 It is possible that the formal structure of intensification, as in old old, is not exactly the same as that of attenuation, which I identify as the meaning of diminutive formations. Attenuation always involves a codomain with more than one member, as I discuss below. I also discuss more than one way of interpreting instances of intensification, in particular as concerns subject- vs. object-oriented modality. At this time, however, I do not have a formal analysis to propose of these two kinds of modality; it is possible that this meaning difference is to be analysed as involving something other than a codomain with two members. It is for this reason that I use the general term relation for the formal character of a rhetorical meaning, as this is neutral between single- and multi-valued functions.

\footnotetext{
*Corresponding author: Susan F. Schmerling, E-mail: susan.schmerling@gmail.com 
The concluding section of this paper, Section 4, suggests a direction for future semantic research that encompasses rhetorical meaning. I emphasise the important role of contextual factors in a comprehensive account of a type of meaning that is based on relations among referential meanings. Pragmatics will play a crucial role in a complete account of rhetorical meaning.

\section{A kind of flat structure and what it means}

\subsection{A confounding example}

Consider example (1):

(1) I saw an old old man.

Sentences like (1) have been held to be problematic for theories deriving syntactic structures exclusively by phrasestructure rules, because such theories assign (1) a structure minimally like that in Figure $1: 2$

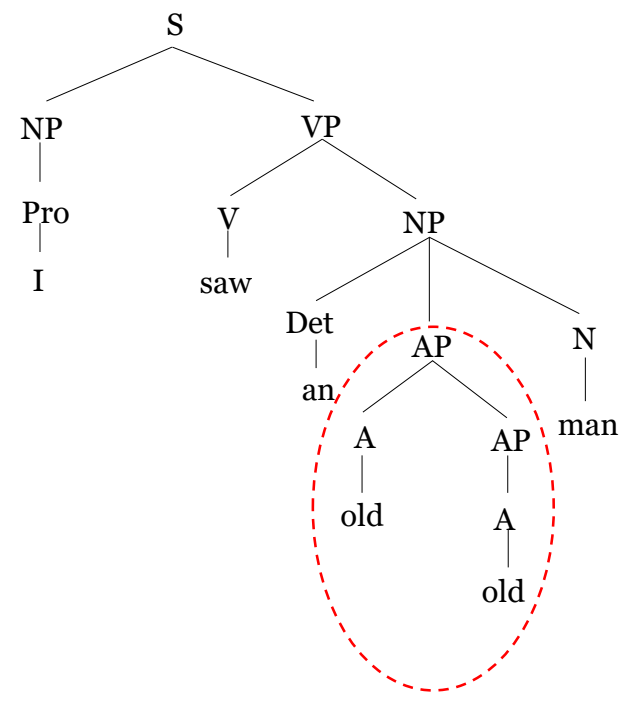

Figure 1. Structure for sentence (1) using only phrase structure rules

The supposition has been that Figure 1 has a structure that is 'too rich'; the problem to which I have just alluded was articulated thus in Chomsky and Miller [3]:

[...] a constituent-structure grammar necessarily imposes too rich an analysis on sentences because of features inherent in the way P-markers are defined for such sentences.

Injustwhat sensethis structure is 'too rich' has notalways been madeclear, although manyyears laterKrivochen[4]noted specifically that if one assumes that scope is to be represented in terms of hierarchical syntactic structure, as with the c-command relation adopted in May [5], then one instance of old c-commands the other, and scope relations are predicted between the occurrences of old that do not occur. ${ }^{3}$

2 Or, in the less theory-neutral Merge-based Minimalism of (Chomsky [1]),

$\left[{ }_{D P}\right.$ an $\left[_{N P}\left[{ }_{A P}\right.\right.$ old $\left[_{A P}\right.$ old $\left[{ }_{N} \cdot L_{N}\right.$ man] $\left.\left.\left.\left.]\right]\right]\right]\right]$,

in which phrase-markers are assumed to be uniformly binary-branching. Any theory from Chomsky [2] onward requires a hierarchical structure as diagrammed in Figure 1 or this footnote.

3 The predicted scope relations would allow for a situation in which, for example, an old man is 50 years old, an old old man is 70 years old, an old old old man (a somewhat anomalous example that is however permitted in the phrase-structure-based analysis under discussion for now) is 90 years old, and so on; see fn. 6 . Our discussion of intensification in what follows shortly should make clear other ways in which the structure in question is an inadequate basis for it to have the meaning it has. 
A structure like Figure 2, which avoids the difficulty to which I have just referred, is generable by a finite-state grammar, which occupies the lowest position in the Chomsky hierarchy of formal languages: ${ }^{4}$

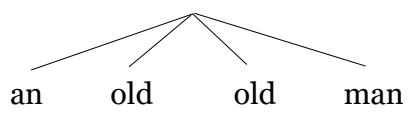

Figure 2. Finite-state structure for an old old man

However, despite the early recognition of a problem of excessive structure, generative syntax went on to reject finite-state aspects of sentence structure in favour of a uniform adherence to the more powerful phrase-structure grammars (see fn. 4); this was the position adopted in Chomsky [2], and it has been maintained throughout the history of mainstream generative grammar. The problem was in fact not revisited until many decades later, when it was taken up in papers by Howard Lasnik and Juan Uriagereka (Lasnik [7]; Lasnik and Uriagereka [8]):

[...] what we need should be, as it were, 'dynamic flatness'. But this is the sort of concept that sounds incomprehensible in a classical computational view, while making sense to those for whom syntactic computations are psychologically real. (Lasnik and Uriagereka, [8], p. 21)

Lasnik and Uriagereka's 'dynamic flatness' proposal has more recently been fleshed out in several works by Diego Gabriel Krivochen; see especially Krivochen [4, 9]; Krivochen and Schmerling, submitted for publication. These more recent proposals, which reject a uniform place for natural-languages in the Chomsky hierarchy, succeed in assigning the desired flat structure to old old in a sentence like (1). ${ }^{5}$ The proposal is specifically a finite-state property of the relevant portion of the sentence (and, in Krivochen's case, the non-monotonic semantics that in his system triggers it). ${ }^{6}$

I propose in this paper that rather than involve syntactic structure, old old in sentence (1) exhibits a phenomenon that is morphological in nature: total reduplication of the adjective, that is, reduplication in which an entire word is doubled, in contrast to various kinds of so-called partial reduplication, in which only a part is doubled. I propose further that the reduplicated character of the old old sequence in (1) has hitherto gone largely unrecognized. (Not entirely, however. Since my original proposal, I have noted the following passage from Sapir [10], Chapter 4, §24:

[Reduplication] is generally employed, with self-evident symbolism, to indicate such concepts as distribution, plurality, repetition, customary activity, increase of size, added intensity, continuance. Even in English it is not unknown [...] Such locutions as a big big man or Let it cool till it's thick thick are far more common [...] than our linguistic textbooks would lead one to suppose).

The context for the Sapir passage is a compendium of grammatical process varieties in the world's languages, without analyses of the specific examples cited. Consider Sapir's sampling in Language (Sapir [10]; §24) of total reduplications from among the languages of the world: ${ }^{7}$

Such cases as Hottentot go-go "to look at carefully" (from go "to see"), Somali fen-fen "to gnaw at on all sides" (from fen "to gnaw at"), Chinook iwi-iwi "to look about carefully, to examine" (from iwi "to appear"), or Tsimshian am' am "several (are) good" (from am "good") do not depart from the natural and fundamental range of significance of the process. A more abstract function is illustrated in Ewe, [...] in which both infinitives and verbal adjectives are formed from verbs by duplication; e.g., yi "to go" yiyi "to go, act of going"; wo "to do," wowo [...] "done"; mawomawo "not to do" (with both duplicated verb stem and duplicated negative particle). Causative duplications are characteristic of Hottentot, e.g., gam-gam [...] "to cause to tell" (from gam "to tell"). Or the process may be used to derive verbs

4 'Theorem 1: for both grammars and languages, Type $0 \supseteq$ Type $1 \supseteq$ Type $2 \supseteq$ Type 3' (Chomsky [6]); where Type 0 = Turing computability/ unrestricted languages; Type 1 = linear bound automata/context-sensitive languages; Type 2 = push-down automata/context-free languages; Type 3 = finite state automata/regular languages.

5 Krivochen $[4,9]$ proposes a model of syntax based on mixed computation that includes an account of this 'dynamism'. Krivochen and Schmerling, submitted for publication, puts the theory in practice with an analysis of coordination as a computationally heterogeneous phenomenon.

6 That is, the semantic value of an NP with multiple occurrences of an adjective, say old, does not increase as the number of instances of old increases.

7 Sapir also offers a sampling of partial reduplications of various kinds. 
from nouns, as in Hottentot khoe-khoe "to talk Hottentot" (from khoe-b "man, Hottentot"), or as in Kwakiutl metmat "to eat clams" (radical element met- "clam").

Now, if we assume for the moment that (total) reduplication is to be accounted for in the syntax, we must ask what its structure must be. We want a reduplication analysis of old old in (1) to yield the desired flat structure, though now not necessarily as the result of finite-state syntax, which would need be justified on independent grounds.

We may give the (somewhat oversimplified) diagram in Figure 3 as an approximation of a structure for (1) that involves reduplication:

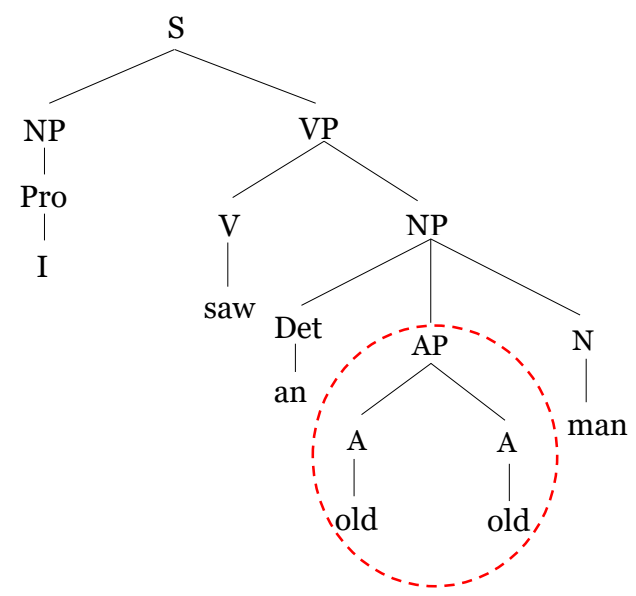

Figure 3. Result of syntactic doubling transformation

Figure 3, an Aspects-vintage tree (though see fn. 2), would result from a copying transformation like the following, where + is an instruction to add a copy of the A in the rule's structural description as a sister of that A:

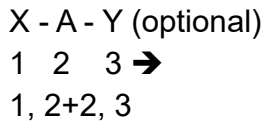

It is not at all clear how any alternative copying transformation could be formulated, in any of the various generative frameworks over the years. Yet the tree in Figure 3 does not in fact contain a reduplicated substructure: it simply contains an AP with twin daughters. ${ }^{8}$

A non-syntactic, morphological approach to old old thus seems eminently desirable. Reduplications are accepted as morphological phenomena, not syntactic ones, by linguists who study morphology-this even though total reduplications are phrases. Linguistics textbooks have long spoken of total and partial reduplications, where total reduplication is the doubling of an entire word. Elisabeth Selkirk's prosodic hierarchy (Selkirk [13, 14]), in which among other things prosodic words make up prosodic phrases, is now widely accepted among specialists in morphology as a framework for understanding reduplication. Crucially, in Selkirk's approach, prosodic words and prosodic phrases are not to be identified with grammatical words and grammatical phrases. Total reduplication is the doubling of a prosodic rather than a syntactic word, and, in the case at hand, it yields a prosodic phrase. Reduplications generally cover a prosodically characterised range more finely tuned than the traditional total/partial distinction suggests, as John McCarthy and Alan Prince [15] demonstrate in their theory of Prosodic Morphology. The recognition of such examples as old old as involving total reduplication solved the problem of syntactic rules producing structures that were 'too rich', and the recognition of total reduplication as morphological, involving headless prosodic structures rather than syntactic structures, now solves the problem of illicit twin heads that arises in a structure like Figure 3 if we identify total reduplication as a syntactic phenomenon.

8 Indeed, Figure 3 has not been a legitimate structure at all since heads were introduced into phrase markers with the advent of X-bar theory (Chomsky $[11,12]$ ), which requires a unique head for every phrase. The structure in Figure 3 is illegitimate within X-bar theory precisely because the AP lacks a head. Alternatively, if a doubled form like that in Figure 3 is to be thought of as headed, then it must have two heads: A Hydra structure in the words of my colleague Diego Gabriel Krivochen. The Hydra, alas, has no reality outside Greek mythology. 
In sum, if old old in (1) is an instance of total reduplication, and if total reduplication is the doubling of a prosodic rather than a syntactic word, then we see how the structure of old old is not and never has been a problem for syntactic theory as such to solve.

So, why have linguists ever been tempted to view a sentence like (1) as involving multiple instances of an adjective in the syntax? The answer is surely because of the observation, in the context of a focus on syntax, that two occurrences of the adjective yielded a more intensive meaning than an otherwise similar sentence with only one adjective. We have arrived at rhetorical meaning generally and intensification in particular.

To see the meaning of English intensive reduplication in perspective, it will be helpful to look at surveys of reduplication in the world's languages. As indicated in the Sapir quotation in fn. 9 (Sapir [10]), '[Reduplication] is generally employed [...] to indicate such concepts as distribution, plurality, repetition, customary activity, increase of size, added intensity, continuance' [emphasis added: SFS]. It must be noted that since the publication of Language in 1921, many more semantic values for reduplication have been documented, some even with meanings that run counter to those listed by him (although the meanings he cites are generally among the first cited, perhaps out of some bias towards iconicity), and the extent to which reduplication is truly iconic is perhaps more open to question today than it was at the time Language was written; see, for example, the discussions of these matters in Inkelas [16]; Key [17]; Moravscik [18]; Rubino [19]. No universal characterisation of its meaning seems to be possible—but, as Sapir noted, there are indeed tendencies that recur in language after language. Sapir was not alone in identifying 'intensity' as a meaning for total reduplication in the languages of the world-especially for modifying expressions, where familiar notions such as 'plurality' that reduplication also often expresses are applicable to nouns rather than adjectives. I have used the term intensive reduplication for the variety of reduplication identified here because it applies to adjectives and yields derived adjectives_or, rather, sets of derived adjectives, which can be viewed pragmatically as candidates for selection in language use. This selection in is highly context dependent, as I have indicated. The meaning of the derived adjectives has a more intensive character than that conveyed by the adjective's base form. This intensive character, in a phrase like an old old man, may pertain to a man of an advanced age that is noteworthy, for which we could also say a very old man; ${ }^{9}$ we might call this an expression of object-oriented epistemic modality, or the degree to which the adjective holds of the modified noun. An old, old man may also, however, pertain to the degree of intensity with which the speaker is articulating the adjective old, where such intensity may pertain to that speaker's perhaps wanting to convey that the use of the word old is what is apt in the context of utterance: 'a genuinely old man (as opposed to the allegedly old man just mentioned)'; these can be seen as instances of subject-oriented modality. ${ }^{10}$ Other specific interpretations can be imagined, depending on the context of utterance.

The meaning I have just described for old old departs from familiar referential meaning in that, as I have indicated, it is in fact a relation between a given referential meaning and a set of candidates for substitution for that meaning, all of which are related to the substituted meaning in a way that is specified by the relation that is the given rhetorical meaning-in this case, intensification. We can summarise this situation by saying that intensity is part of the meaning of the construction. This is what indicates that the intensive character of old old in (1) is rhetorical rather than strictly referential in nature: application of the reduplication itself has the semantic value of substituting a more intensive referential meaning for a less intensive one.

\section{A second rhetorical meaning: diminutive formations}

Having argued for the existence of specifically rhetorical meaning, I would now like to bolster my argument with discussion of a further case of what I believe is best viewed as a meaning relation that is rhetorical in nature. This case involves morphosyntactic structures that are quite different from old old's reduplication.

The languages I will be focussing on in this section are Spanish and, perhaps surprisingly, English. Contemporary English is generally thought of as lacking productive diminutives; I maintain, however, that English simply has

9 Very often occurs in two iterations, but this is not necessary—in the example in the text there is only one —and three or more iterations are also possible:

(i) a very, very, very old man

Examples like (i) indicate that very does not involve reduplication. Here a finite-state property of a subset of well-formed English strings would indeed appear to be in evidence.

10 I owe these observations concerning subject- and object-oriented epistemic modality to Diego Gabriel Krivochen. On subject-oriented modality, see especially Palmer [20], and de Haan [21]. 
phrasal, or, if you will, analytic diminutives employing the word little as an auxiliary, ${ }^{11}$ as in the title of the 1940 comedy-western My Little Chickadee (Cline [22]), which starred Mae West and W.C. Fields. ${ }^{12}$

Whether synthetic or analytic, diminutives have attracted attention in part because of an observed crosslinguistic tendency for them to indicate something beyond relative smallness, this extra element of meaning often thought of as a connotation of endearment. ${ }^{13}$

This section argues, however, that it is wrong to identify relative smallness as the essential meaning of diminutives. In Section 3.3, I will argue for a more fundamental meaning for them and further argue that it meets the criteria identified in Section 2 for meaning that is rhetorical in nature.

\subsection{English}

Productive contemporary English diminutives have the appearance of adjective-noun NPs, the adjective being little (as opposed to small, which pertains strictly to size, or, in the case of time and distance, extent): ${ }^{14}$

(2) How's my little Fluffy this morning?

(3) Here's my little home-sweet-home.

Example (2) might be a way of greeting an adored pet. And (3) could in fact express an attitude of endearment towards a house that was in fact very large, so that smallness is in no way essential to the meaning. ${ }^{15}$

English diminutives can have positive connotations, as we have seen, but negative connotations are possible as well, as we will see shortly. The understanding of a diminutive form as having a positive or negative connotation is, in fact, one of their characteristically context-dependent features. Consider that a proud parent could refer to a young son (little boy) as in (4):

(4) my little man

However, the phrase little man can have connotations not of endearment or pride but of contempt: a grown man referred to this way, even one who holds a respected position but is in fact viewed as petty and vindictive, may well be spoken of as a little man, as in the headline in (5): ${ }^{16}$

(5) Trump is a little man with little hands.

A notorious diminutive 'contempt' connotation is reportedly due to the late American hotelier Leona 'Queen of Mean' Helmsley, of whom the Wikipedia [24] writes:

After allegations of non-payment by her of contractors hired by her to build her home, Helmsley was investigated and convicted of federal income tax evasion and other crimes in 1989 [...] During the trial, a former housekeeper testified that she had heard Helmsley say: 'We don't pay taxes; only the little people pay taxes', an [aphorism] which identified her the rest of her life.

It must not be thought that the contempt interpretation I have identified is somehow related to the fact that (productive) English diminutives are phrasal. As we will see, an analogous situation can obtain in Spanish, where they are not.

11 I am here making a terminological analogy to the traditional use of analytic for examples such as Romance phrasal counterparts of single-word Latin verb forms, as in the French passive est aimé(e) 'is loved', in contrast to the single-word, or synthetic, amatur of Latin.

12 https://www.youtube.com/watch?v=7RrniElxRI0\&list=PLcT_t__UlyRwnUm1WJ8gtoE3wJQe_8Y_H I am indebted to Knud Lambrecht for offering this example of an English analytic diminutive using little.

13 My discussion of the range of diminutive interpretations owes much to fruitful dialogue with Diego Gabriel Krivochen and Hans Kamp.

14 An analogous situation exists in contemporary French, where phrasal diminutives are productively formed with petit 'little'. A well known example is the sobriquet of Napoléon Bonaparte, le petit caporal 'the little corporal'.

15 Some English little diminutives have become lexicalised: little woman 'wife'. This is true of French analytic diminutives as well: petit-fils 'grandson' (cf. fils 'son'). As with morphological formations generally, lexicalisation is also well attested among languages that have productive synthetic diminutives; note, for example, Spanish pera 'chin', perilla 'goatee'.

16 From Jordan-McCollough [23]. 


\subsection{Spanish}

Spanish (synthetic) diminutives are commonly formed with the suffix -ito (unmarked)/-ita (feminine) (though these are not the only such suffixes, variation among which is on the whole phonologically but sometimes lexically conditioned):

(6) a. papel 'paper'; 'part (in a play)'

b. papelito 'slip of paper'; 'bit part'

(7) a. casa 'house'

b. casita 'little house', 'cottage'

The reader wishing an introductory survey of Spanish diminutives may want to consult webpages such as [25] or [26]. My intention in this section is not to offer an original summary but rather to show that Spanish diminutives can have the same interpretations as those we have seen for English. The range of Spanish diminutive interpretations is indeed broader than that for English; this is because diminutive formatives may be suffixed to items of a variety of grammatical classes, whose referential meanings are therefore of more than one type-though which classes can host diminutive suffixes is subject to considerable variation among national and regional dialects.

The NP in (8), taken from Bartens and Sandström [27], p. 333, illustrates co-occurrence with adjectives of the suffixes I illustrated in (6) and (7), in addition to co-occurrence with a noun; the full gloss in (8) is my own, a modification of Bartens and Sandström's:

(8) (...) uno de esos muchachitos linditos, riquitos, hijos de papá que me fascinan (también). [(Colombian author Fernando Vallejo [28])]

'one of those pretty-dim, rich-dim boys-dim, spoiled brats who fascinate me (as well)'

Note that in (8), of the three diminutive forms muchachitos (nominal base muchacho; $-s$ is the plural desinence), linditos (adjectival base lindo), and riquitos (adjectival base rico), only the first is a noun, and so only that form can readily be thought of as expressing 'little <base>'- but in fact, (8) presents not an evaluation of its referents' size at all but rather disparagement of them.

My colleague Diego Gabriel Krivochen has provided me with what may be Argentina's answer to Only the little people pay taxes, from a satirical piece in the newspaper LA NACION by Carlos M. Reymundo Roberts [29], entitled 'Desesperada carta a Cristina Kirchner' 'A desperate letter to [highly controversial former president of Argentina and then candidate for what would have been a powerful Senate seat] Cristina Kirchner'.

No puedo hacerme a la idea de que vamos a tener un país sin usted, o con usted en un papel menor, tristón, una senadorita a la que nadie toma en serio y que se queda dormida en su banca mientras habla un tal Mayans, un cuatro de copas de Formosa. [emphasis added: SFS]

'I can't get used to the idea that we're going to have a country without you, or with you in a minor, pitiable role, a little senator who no one takes seriously and who stays asleep at her desk while [an obscure senator] speaks, [a nobody from a remote province]. [emphasis added: SFS]

Here, una senadorita conveys 'an insignificant senator'.

\subsection{The rhetorical nature of the meaning of diminutives}

Bartens and Sandström [27], note (p. 333) that their corpora contain diminutive formations built on bases from a broad range of grammatical classes, including past participles; adverbs; personal, demonstrative, and interrogative pronouns; numerals; interjections and greetings; phrases; and gerunds.

In this paper I decline to cite examples from Bartens and Sandström's remaining categories, in part because it is likely that no one dialect has diminutive forms in all the categories in their data store-and because I believe that the noun- and adjective-based examples we have looked at already have a lot to tell us. 
Let us return to example (8), which contains a mix of nominal and adjectival diminutive forms. In (8) it would make sense, in principle, to gloss muchachitos as 'boys who are small', in keeping with the usually cited meaning of diminutives. But (8) does not mean this, as I indicated earlier: the boys are described not as small in stature but rather as objects of disparagement on the part of the narrator. The adjectival linditos and riquitos, as constituents of noun phrases that express disparagement, continue this disparaging theme but do not make sense as 'little' variants of lindos 'pretty' and ricos 'rich'; what would a small-sized counterpart of 'pretty' or 'rich' be? As I have emphasized, however, they have meanings that are in no way nonsensical. How is it that these three expressions can express disparagement?

Most of the examples of nominal diminutives cited in Section 3.2 had negative connotations, but this was an accident of the points I chose to focus on. As with the English discussion in Section 3.1, both positive and negative interpretations are represented, and so one of the things we have to account for is the fact that such seemingly contradictory interpretations can arise in both English and Spanish diminutives. We have also seen that Spanish diminutive bases need not be nominal. Here we must account for the fact that a single set of affixes can yield coherent interpretations with categorially varied bases.

I suggest that this variability in the grammatical categories to which diminutive formatives can be added tells us more about their fundamental character than does the appearance of variation, sometimes to the point of contradiction, in the interpretations of diminutive formations themselves. I propose (9) as the essence of diminutive meanings:

(9) The addition of a diminutive formative to a base of any category, as a given variety of a language permits, results in an attenuation of the referential meaning of that base.

Consider the contradictory interpretations of little man discussed in Section 3.1. Where this was an endearing description of a child by a proud parent, the meaning of man was attenuated enough to give it an interpretation of lack of attainment of physical maturity. Where this same diminutive phrase was applied to a grown man, attenuation of the meaning of man also gave man the interpretation of one lacking attainment of maturity, but here the appropriate lack of attainment was in moral maturity. 'Positive' and 'negative' evaluations were secondary.

\section{Conclusion}

My point of departure in this paper was an infrequently discussed but very real problem for theories of syntactic phrase markers based exclusively on phrase-structure rules (generative theories from Chomsky [2] onward). Such theories have been forced to assign an NP like an old old man an 'overly rich' structure (Chomsky and Miller [3]) that wrongly predicts scope readings that do not in fact occur: A problem that is avoided if old old has the flat structure that a finite-state grammar would assign it. I proposed that the requisite flat structure was to be understood as an instance of total reduplication - that the solution to the problem of 'overly rich structure' was not a matter of modifying the permissible rules generating phrase markers but was instead a matter of morphology, here involving prosodic phrases in the sense of Selkirk [13,14].

$I^{17}$ further argued that the meaning of what I called intensive reduplication was rhetorical in nature, inasmuch as its meaning was best understood as the substitution of one referential meaning for a related one, the substituted meaning selected in context from a set of candidate meanings that are made available by the relation expressing the rhetorical meaning in question, here intensification. An aspect of the meaning of old old that I have emphasised is the range of interpretations that it is allowed to have, and the fact that the choice of interpretation is highly contextdependent.

The paper continued by seeking to bolster the notion of rhetorical meaning with the study of another instance of such meaning as it manifested itself in diminutive formations. We distinguished analytic, or phrasal, diminutives, which exist in English and French, from synthetic, or word-level diminutives, the type recognised traditionally. Basing our analysis on data primarily from English and Spanish, the latter having productive synthetic diminutives, we arrived at a rhetorical meaning for a diminutive formative: attenuation of the referential meaning of the base with which it is construed.

17 In this context, see especially McCarthy and Prince [15] 
This rhetorical ${ }^{18}$ meaning holds for English and French as well, although diminutive formatives apply to fewer grammatical categories in English and French than they do in Spanish, and therefore the applicable referential meanings are fewer.

The examples we have looked at-intensification and attenuation of referential meanings-pertain to a substitution of one referential meaning for an alternate one, the particular substitution depending on the rhetorical meaning at hand. We justified the term rhetorical meaning for this meaning substitution by means of an analogy with the tropes of classical rhetoric.

I have emphasised that a rhetorical meaning is a relation from what, borrowing from morphological terminology, we might call a base meaning, to a set of derived meanings, the particular set of course depending on the rhetorical meaning in question. We have looked at two of these: intensification and attenuation. I have also emphasised that a significant feature of rhetorical meanings is that with each one, the choice of a specific derived meaning is highly dependent on context. A complete account of rhetorical meanings must incorporate an account of this context dependence. Rhetorical meanings are not alone in being situated at, one might put it, the interface of semantics and pragmatics.

\section{Acknowledgments}

Profound thanks are due Ann Welden for provocative and insightful comments on earlier drafts of this paper, to Andy Rogers for suggesting numerous clarifications, and to Diego Gabriel Krivochen, José-Luis Mendívil, Juan Romero Morales, Francisco Ordóñez, Idoia Ros, and Mercedes Tubino for serving as informants for Spanish. I am also greatly indebted to Hans Kamp and, especially, Diego Gabriel Krivochen for stimulating discussion of the ideas on which this paper is based; Krivochen deserves additional gratitude for detailed feedback on earlier drafts as well as general help and encouragement. I assume complete responsibility for all errors.

18 Diego Gabriel Krivochen points out that this analysis of diminutives as involving attenuation of the meaning of their base makes the prediction that only bases denoting gradable properties allow for the diminutive. And this indeed seems to be the case: *verdaderito (< verdadero 'true'), *muertito (< muerto 'dead')

\section{References}

[1] Chomsky, N., 1995. The Minimalist Program. Cambridge, Massachusetts, USA: MIT Press.

[2] Chomsky, N., 1965. Aspects of the theory of syntax. Cambridge, Massachusetts, USA: MIT Press.

[3] Chomsky, N., Miller, G. 1963. Introduction to the formal analysis of natural languages. In Luce, Duncan R.; Bush, R.; Galanter, E. (Eds.), Handbook of mathematical psychology 2, 269-321. New York, New York, USA: Wiley.

[4] Krivochen, D., 2015. On phrase structure building and labeling algorithms: Towards a non-uniform theory of syntactic structures. The Linguistic Review, 32(3): 515-572.

[5] May, R., 1977. The grammar of quantification. PhD dissertation, MIT, Cambridge, Massachusetts, USA.

[6] Chomsky, N., 1959. On certain formal properties of grammars. Information and Control, 2: 137-167.

[7] Lasnik, H., 2011. What kind of computing device is the human language faculty? In Di Sciullo, A., Boeckx, C., (Eds.), The biolinguistic enterprise:
New perspectives on the evolution and nature of the human language faculty, 354-365. Oxford, UK: Oxford University Press.

[8] Lasnik, H., Uriagereka, J., 2012. Structure. In Kempson, R., Fernando, T., Asher, N., (Eds.), Handbook of philosophy of science, volume 14: Philosophy of linguistics, 33-61. Amsterdam, Netherlands: Elsevier.

[9] Krivochen, D., 2018. Aspects of emergent cyclicity in language and computation: Arguments for mixed computation. PhD thesis, University of Reading, Reading, UK.

[10] Sapir, E., 1921. Language. New York, New York, USA: Harcourt, Brace.

[11] Chomsky, N., 1970b. Remarks on nominalization. In Jacobs, R., Rosenbaum, P., (Eds.), Readings in English transformational grammar, 184-221. Waltham, Massachusetts, USA: Ginn and Company.

[12] Chomsky, N., 1986. Barriers. Cambridge, Massachusetts, USA: MIT Press. 
[13] Selkirk, E., 1981. On prosodic structure and its relation to syntactic structure. In Fretheim, T., (Ed.), Nordic prosody II: Papers from a symposium, 11140. Trondheim, Norway: TAPIR.

[14] Selkirk, E., 2011. The syntax-phonology interface. In Goldsmith, J., Riggle, J., Yu, A., (Eds.), The handbook of phonological theory, second edition. Oxford, UK: Blackwell.

[15] McCarthy, J., Prince, A., 1996. Prosodic Morphology. In Goldsmith, J. (Ed.), The handbook of phonological theory, 283-305. Oxford, UK: Blackwell. Also available at: <http://www. mikettpham.com/wp-content/uploads/2015/09/ McCarthy1998-Prosodic-Morphology.pdf>.

[16] Inkelas, S., 2014. Non-concatenative derivation: Reduplication. In Lieber, R., Stekauer, P., (Eds.), The Oxford handbook of derivational morphology: Oxford surveys in syntax and morphology, 8. Oxford, UK: Oxford University Press.

[17] Key, H., 1965. Some semantic functions of reduplication in various languages. Anthropological Linguistics, 7: 88-101.

[18] Moravscik, E., 1978. Reduplicative constructions. In Greenberg, J., (Ed.), Universals of human language, vol. 3: Word structure, 297-334. Palo Alto, California, USA: Stanford University Press.

[19] Rubino, C., 2005. Reduplication: Form, function, and distribution. In Hurch, B., Mattes, V., (Eds.), Studies on reduplication, 11-29. New York, New York, USA: Mouton De Gruyter.

[20] Palmer, F., 1986. Mood and modality (Cambridge textbooks in linguistics). Cambridge, UK: Cambridge University Press.

[21] de Haan, F., 2004. Typological approaches to modality. In Frawley, W., (Ed.), Modality, 27-70.
Berlin, Germany: Mouton de Gruyter.

[22] Cline, E., (Director). (1940). My little chickadee [Motion picture]. Hollywood, California, USA: Universal Studios.

[23] Jordan-McCollough, M., 2017. Trump is a little man with little hands [Letter to the editor]. MyrtleBeachOnline.com, available at: <http://www. myrtlebeachonline.com/opinion/letters-to-theeditor/article164720077.html>.

[24] Leona Helmsley, 2017. In Wikipedia, available at: $<$ https://en.wikipedia.org/wiki/Leona_Helmsley>.

[25] Spanish diminutives, augmentatives, and more... (n.d.), in Spanish411.net, available at: <http:// www.spanish411.net/Spanish-DiminutivesAugmentatives.asp $>$.

[26] Using diminutives in Spanish. (n.d.), in Happy hour Spanish, available at: <https://www. happyhourspanish.com/those-little-diminutives-inspanish/>.

[27] Bartens, N., Sandström, A., 2006. Towards a description of Spanish and Italian diminutives within the Natural Semantic Metalanguage framework. In Peeters, B., (Ed.), Semantic primes and universal grammar, 333-360. Amsterdam, Netherlands: John Benjamins.

[28] Vallejo, F., 1994. La virgen de los sicarios (The virgin of the hired guns), Madrid, Spain: Alfaguara.

[29] Reymundo Roberts, C., 26 August 2017. Desesperada carta a Cristina Kirchner (Desperate letter to Cristina Kirchner). LA NACION, available at: <http://www.lanacion. com.ar/2056761-desesperada-carta-a-cristinakirchner?utm_campaign=Echobox\&utm_ medium=Echobox\&utm_source=Facebook\#link_ time $=1503746525>$. 